\title{
ANÁLISE DE AGRUPAMENTO EM ÁREA DE POTENCIAL EÓLICO NA REGIÃO DO SUBMÉDIO SÃO FRANCISCO
}

\author{
Pollyanna Kelly de Oliveira Silva ${ }^{1,3,6}$, Samira de Azevedo Santos ${ }^{1,4}$, Maria Regina da Silva \\ Aragão $^{2}$, Magaly de Fatima Correia ${ }^{2}$, Wenderson Silva dos Santos ${ }^{5}$ \\ ${ }^{1} \mathrm{PPG}$ em Meteorologia/CTRN/UFCG, Campina Grande, PB, Brasil \\ ${ }^{2}$ DCA/CTRN/UFCG, Campina Grande, PB, Brasil \\ ${ }^{3}$ IMPSA, Cabo de Santo Agostinho, PE, Brasil \\ ${ }^{4}$ CTGÁS-ER, Natal, RN, Brasil \\ ${ }^{5}$ Graduação em Estatística,UEPB, Campina Grande, Brasil \\ ${ }^{6}$ pollyanna_kelly@yahoo.com.br
}

\section{RESUMO}

Neste trabalho a técnica multivariada da Análise de Agrupamento (AA) é empregada com o objetivo de caracterizar os padrões de variabilidade temporal do vento na área do Submédio do São Francisco (SSF). Dados de velocidade do vento na altura de $25 \mathrm{~m}$ e $50 \mathrm{~m}$, disponibilizados pelo projeto SONDA do INPE para a cidade de Petrolina, referentes ao período 2007-2010, são utilizados. A AA possibilitou identificar meses homogêneos e anos anômalos, bem como regimes de velocidades mínimas e máximas na região do SSF. De maneira geral, nos grupos de meses que apresentam velocidades do vento mais elevadas, haverá maior eficiência no aproveitamento do recurso eólico da região.

\begin{abstract}
In this work the multivariate technique of cluster analysis (CA) is applied aiming to characterize temporal variability patterns of the wind in the Submiddle São Francisco (SSF). Wind speed data collected at heights of $25 \mathrm{~m}$ and $50 \mathrm{~m}$ during 2007-2010, made available by the SONDA project of INPE for the city of Petrolina, are used. The CA allowed to identify homogeneous months and anomalous years, as well as regimes of minima and maxima wind speeds in the SSF. In general, in the groups of months that show stronger wind speeds the efficiency in the wind power production will be higher.
\end{abstract}




\section{INTRODUÇÃO}

As energias alternativas ou renováveis têm sido uma das soluções utilizadas para suprir a demanda energética que vem aumentando nos últimos anos devido ao crescimento das atividades econômicas e da melhoria da qualidade de vida, já que apresentam baixo impacto ambiental e são auto sustentáveis.

A geração eólica vem se tornando realidade no País como fonte energética devido à complementaridade entre a geração hídrica e eólica, o que impulsiona o avanço dessa fonte. A região Nordeste é um bom exemplo, já que nela o maior potencial eólico ocorre durante o período de menor disponibilidade hídrica. Atualmente, é possível observar grandes investimentos realizados na área do Submédio São Francisco para estas duas fontes energéticas.

Neste trabalho o objetivo é caracterizar os padrões de variabilidade temporal do vento nas alturas de $25 \mathrm{~m}$ e $50 \mathrm{~m}$, a partir da técnica multivariada da Análise de Agrupamento (AA), ou "Cluster Analysis", para a região do Submédio São Francisco (SSF), em um período de quatro anos.

\section{MATERIAL E MÉTODOS}

O estudo foi realizado para a região do Submédio São Francisco, utilizando registros provenientes da torre anemométrica situada na cidade de Petrolina disponibilizados pelo projeto SONDA do INPE. Os dados anemométricos contemplam o período de 2007 a 2010 , medidos na altura de $25 \mathrm{~m}$ e $50 \mathrm{~m}$, com registros de 10 em 10 minutos.

A AA foi aplicada seguindo a proposta de Ward (1963), com medida de distância euclidiana quadrática, para análise no modo-S, que tem por objetivo identificar condições climáticas específicas. A determinação do número de grupos no dendrograma foi realizada de maneira visual, utilizando a técnica de inércia de saltos. 


\section{RESULTADOS E DISCUSSÕES}

A AA aplicada aos dados de velocidade do vento nas alturas de $25 \mathrm{~m}$ e $50 \mathrm{~m}$ na região do SSF possibilitou distinguir quatro grupos homogêneos com uma distância reescalonada de 12 e 15, respectivamente (Figura 1 a-b).

Velocidades do vento a $25 \mathrm{~m}$ da superfície resultaram nos seguintes meses homogêneos: Grupo I (dezembro, janeiro, março, abril, maio), Grupo II (fevereiro), Grupo III (julho, agosto e outubro) e Grupo IV (junho, setembro e novembro).

As velocidades de vento a $50 \mathrm{~m}$ da superfície resultaram nos mesmos meses homogêneos das medições a $25 \mathrm{~m}$, mas com as distâncias reescalonadas entre os grupos diferentes: Grupo I (junho, setembro e novembro), Grupo II (julho, agosto e outubro), Grupo III (dezembro, janeiro, março, abril, maio) e Grupo IV (fevereiro).

$\mathrm{Na}$ altura de medição de $25 \mathrm{~m}$ (50 m) os meses do Grupo III e IV (Grupo II e III) apresentam as maiores intensidades do vento, se comparados com os meses do Grupo I e II (Grupo III e IV). Essa variabilidade nos padrões de vento está associada à atuação da alta subtropical do Atlântico Sul.

Destaca-se entre os grupos de meses homogêneos obtidos na altura de medição de $25 \mathrm{~m}$ (50 m), aquele que contempla apenas o mês de fevereiro, Grupo II (Grupo IV) (Fig.1a-b), já que nele as médias mensais da velocidade do vento são as mais baixas. Além disso, este mês apresenta o maior índice de precipitação da região no período de estudo (2007-2010) (http:// www.apac.pe.gov.br/meteorologia/).

Nos resultados obtidos para os padrões homogêneos anuais a $50 \mathrm{~m}$ (Fig. 1c), foram formados dois grupos com distância reescalonada de 5. O primeiro é composto pelos anos de 2008, 2009 e 2010, que mostram similaridades, já que foram considerados anos com regime de circulação atmosférica normal. (CLIMANÁLISE, 2008-2010).

O ano de 2007 não se associa ao grupo anterior, formando assim o segundo grupo (Fig. 1c). Essa formação deve-se principalmente ao posicionamento dos VCAN e à atuação da ZCIT mais ao sul da sua climatologia (CLIMANÁLISE, 2007), gerando episódios extremos de precipitação na região do SSF e ocasionando inundações e perdas materiais, especialmente no mês de fevereiro. 

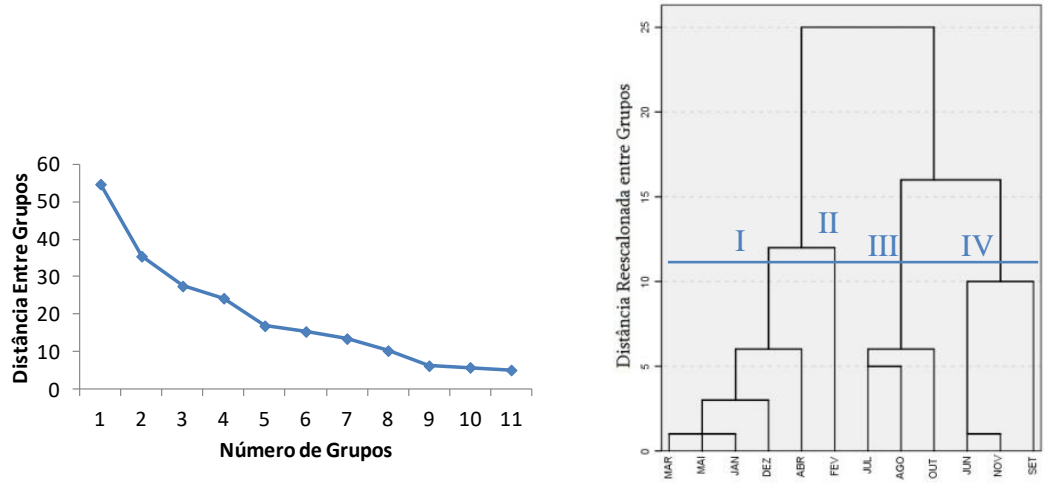

(a)
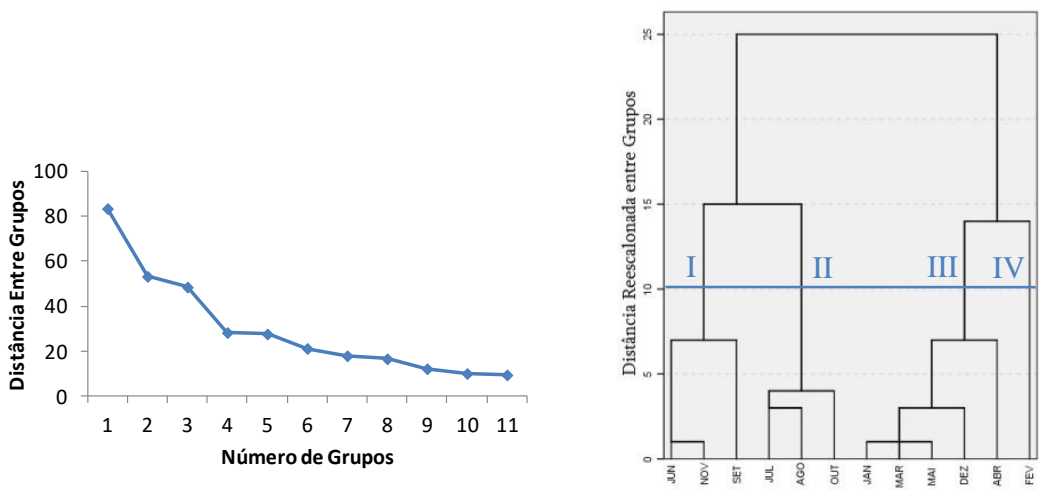

(b)
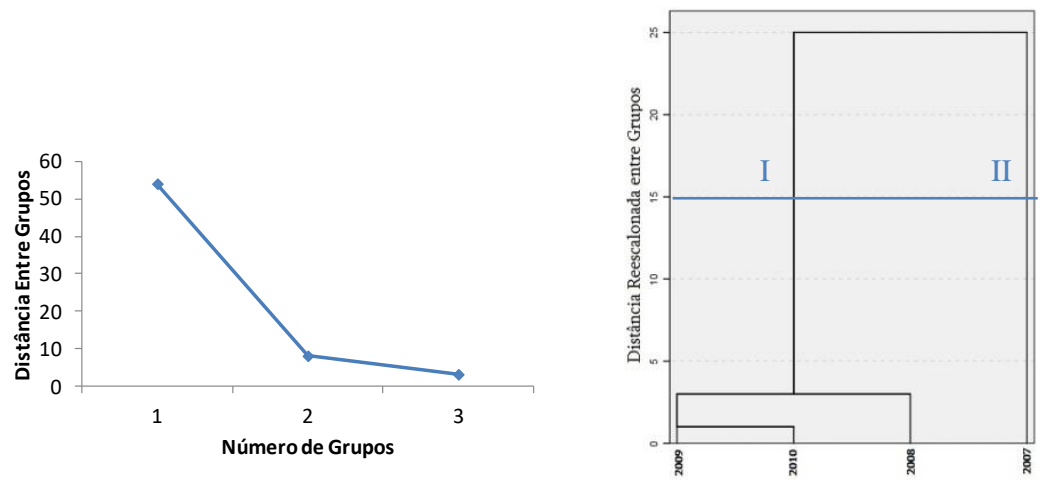

(c)

Figura1- Curva de inércia e dendrograma para: definição de meses homogêneos dos anos de 2007 a 2010 na altura de (a) $25 \mathrm{~m}$ e (b) $50 \mathrm{~m}$, e (c) definição de anos homogêneos usando os meses de janeiro a dezembro para a altura de $50 \mathrm{~m}$. 


\section{CONCLUSÕES}

A AA possibilitou identificar meses homogêneos e anos anômalos na região do SSF. Os padrões de vento nas duas alturas mostraram regimes de velocidades mínimas e máximas, como também padrão de anomalia mensal e anual. De maneira geral, nos grupos de meses que apresentam velocidades do vento mais elevadas, haverá maior eficiência no aproveitamento do recurso eólico da região. As associações formadas estão relacionadas à atuação de sistemas atmosféricos de diferentes escalas como: Alta Subtropical do Atlântico Sul, Zona de Convergência Intertropical, Zona de Convergência do Atlântico Sul, Vórtices Ciclônicos de Altos Níveis, sistemas de mesoescala e de circulações locais em diversas épocas do ano.

\section{REFERÊNCIAS}

CLIMANÁLISE. Cachoeira Paulista-SP: INPE/CPTEC, 2007-2010. Mensal. Boletim de Monitoramento e Análise Climática. ISSN 0103-0019 CDU-555-5.

WARD, J. H. Hierarchical grouping to optimize an objective function. Journal of the American Statistical Association. Alexandria, v.58, n.301, p.236-244, 1963. 